\title{
Delineating the distinct role of AKT in mediating cell survival and proliferation induced by CD154 and IL-4/IL-21 in chronic Iymphocytic leukemia
}

\author{
Elinor A. Chapman ${ }^{1}$, Melanie Oates ${ }^{1}$, Ishaque S. Mohammad ${ }^{1}$, Barry R. Davies ${ }^{2}$, Paul \\ K. Stockman ${ }^{2}$, Jianguo Zhuang ${ }^{1}$ and Andrew R. Pettitt ${ }^{1,3}$ \\ ${ }^{1}$ Department of Molecular and Clinical Cancer Medicine, University of Liverpool, Liverpool, UK \\ ${ }^{2}$ Oncology iMED, AstraZeneca, Cambridge, UK \\ ${ }^{3}$ Royal Liverpool and Broadgreen University Hospitals NHS Trust, Liverpool, UK \\ Correspondence to: Jianguo Zhuang, email: j.zhuang@liverpool.ac.uk
}

Keywords: CLL; CD40 stimulation; AKT; proliferation; survival

Received: November 16, $2016 \quad$ Accepted: October 25, $2017 \quad$ Published: November 07, 2017

Copyright: Chapman et al. This is an open-access article distributed under the terms of the Creative Commons Attribution License 3.0 (CC BY 3.0), which permits unrestricted use, distribution, and reproduction in any medium, provided the original author and source are credited.

\section{ABSTRACT}

The functional significance of AKT in chronic lymphocytic leukemia (CLL) remains unclear. Given the importance of non-malignant $T$ cells in regulating clonal expansion in CLL, we investigated the role of AKT in T cell-mediated cytoprotection and proliferation using an established co-culture system in which primary CLL cells were incubated on a monolayer of transfected mouse fibroblasts expressing human CD40L (CD154). Stimulation of CLL cells via CD40 induced activation of AKT, which was closely associated with downregulation of its negative regulator PTEN, and protected CLL cells from killing by bendamustine. This cytoprotective effect of CD40 stimulation was prevented by a selective inhibitor of AKT. Stimulation of CLL cells with CD154 + IL-4 or IL-21 induced proliferation detected as reduced fluorescence of cells pre-stained with CFSE. AKT inhibition produced a significant, consistent reduction in proliferation induced by CD154 + IL-4 and a reduction in proliferation induced by CD154 + IL-21 in most but not all cases. In contrast, AKT inhibition had no effect on the proliferation of normal B cells induced by CD154 + IL-4 or IL-21. These findings indicate that AKT contributes in a significant way to T-cell mediated survival and proliferation signalling in CLL and support the clinical evaluation of AKT inhibitors in this disease.

\section{INTRODUCTION}

Chronic lymphocytic leukemia (CLL) is a malignancy of $\mathrm{CD}^{+} \mathrm{B}$ lymphocytes that accumulate in the blood, bone marrow and secondary lymphoid tissues such as lymph nodes. It is the most common form of leukemia in adults in the Western countries [1]. Despite recent therapeutic advances involving purine analogues and monoclonal antibodies [2], the disease remains incurable, and new therapeutic agents are therefore urgently required.

Although the biology of CLL is still unclear $[3,4]$, disease pathogenesis is most likely influenced by microenvironmental factors in affected tissues. It is now accepted that chronic stimulation of the B-cell receptor
(BCR) by antigen plays a key role in maintaining and expanding the malignant clone [5-7]. However, the survival and proliferation of CLL cells are also thought to depend on their interactions with accessory cells $[8,9]$. One important interaction involves stimulation of CD40 on CLL cells by CD40 ligand (CD40L or CD154) on non-malignant $\mathrm{T}$ cells in affected lymph nodes $[10,11]$. Such cross-talk between CLL cells and accessory cells has been increasingly recognized to play an important role in disease progression, most likely through the activation of certain pro-survival or mitotic signalling pathways.

One such pathway involves phosphatidylinositol 3-kinase (PI3K). The latter regulates a variety of important biological processes including cell growth, survival, 
migration, and metabolism $[12,13]$. Particularly relevant to CLL is the fact that PI3K can be activated by diverse stimuli that include antigens, cytokines and chemokines, as well as adhesion molecules $[14,15]$. Indeed, the aberrant activation of PI3K has been reported to contribute to the survival of CLL cells $[16,17]$. Thus targeting the PI3K pathway becomes an attractive strategy for development of novel therapeutic agents. In fact, the novel PI3K p1108 isoform-specific inhibitor, idelalisib, has significant clinical activity in CLL and is now approved for this indication [18-20]. Mechanistically, idelalisib has been shown to exhibit multiple modes of action - directly decreasing cell viability and disrupting interactions that retain CLL cells in protective tissue microenvironments [21, 22], but also inducing egress of CLL cells from the lymph nodes [23].

The serine/threonine kinase AKT (also known as protein kinase $\mathrm{B}, \mathrm{PKB}$ ) is an important downstream effector of PI3K as it is largely responsible for PI3Kmediated pro-survival signalling $[24,25]$. AKT is also involved in regulation of other cellular processes including angiogenesis, metabolism, growth/proliferation, protein synthesis and transcription $[24,26]$. Dysregulation of AKT has thus been closely linked to the development of many human diseases including cancer $[27,28]$.

We and others have previously shown that AKT is critically involved in CLL cell-survival [29-32]. Pharmacological inhibition of AKT reduces the survival of CLL cells ex vivo under standard conditions [31,33], indicating that AKT inhibitors may have therapeutic potential in CLL. However, given that the survival and proliferation of CLL cells is closely regulated by the CLL microenvironment, it is important to understand the effect of AKT inhibition in CLL cells that are exposed to relevant stimuli. To this end, we co-cultured primary CLL cells on a stromal monolayer of transfected mouse fibroblasts expressing human CD154 to mimic the lymph node microenvironment and explored the distinct effects of AKT in mediating the survival, growth and proliferation of CLL cells induced by CD40 stimulation.

\section{RESULTS}

\section{Stimulation of CLL cells via CD40 induces AKT activation and reduced expression of PTEN irrespective of the presence of IL-4 or IL-21}

We have previously shown that CD40 stimulation (achieved by co-culturing CLL cells with CD154expressing fibroblasts) protected leukemic cells from killing by cytotoxic agents that induce apoptosis through activating the intrinsic mitochondrial or extrinsic death receptor-mediated pathway [34]. Although the cytoprotective effects of CD40 stimulation are known to be largely mediated by the transcription factor NF- $\mathrm{KB}$ [11], stimulating CLL cells with soluble CD40 ligand also resulted in activation of AKT, as measured by increased phosphorylation at serine 473 [21, 35, 36]. To establish whether AKT is also activated by membrane-bound CD40 ligand, levels of phospho-AKT (p-AKT) were measured in primary CLL cells cultured on an adherent monolayer of CD154-expressing fibroblasts. As shown in Figure 1A, the level of p-AKT was consistently increased in CLL cells upon CD40 stimulation when compared to cells cocultured with control parental cells over a period of 72 h. Furthermore, the total AKT in CD40-stimulated cells appeared to be mostly located in a higher molecular weight band (Figure 1A), suggesting that most of it becomes phosphorylated. It was also noted that the level of total AKT was reduced when it was phosphorylated. Since the p-AKT and total AKT were probed on 2 separate membranes, reduction of total AKT is thus likely caused by the accelerated proteasomal degradation of $\mathrm{p}$-AKT that serves as a negative feedback mechanism to terminate AKT activation [37]. To confirm that the CLL cells had been stimulated via CD40, we measured expression of $B C L-X_{L}$ as a surrogate marker of such stimulation [34]. As expected, BCL- $\mathrm{X}_{\mathrm{L}}$ was up-regulated in CLL cells cocultured with CD154-expressing fibroblasts throughout the $72 \mathrm{~h}$ incubation period (Figure 1A). The pooled densitometry data analysis showed that the increase in p-AKT following CD40 stimulation was maximum at $24 \mathrm{~h}$ when levels were 2-fold higher compared with CLL cells that had been co-cultured with the parental fibroblasts $(P<0.05)$ (Figure 1B).

To understand how CD40 stimulation might increase AKT phosphorylation, we investigated its effect on the expression of PTEN (the major negative regulator of PI3K/AKT [38]). Experiments were performed in the presence or absence of interleukin (IL)-4 or IL-21, both of which are produced by T cells and enhance and/ or modulate the effect of CD40 stimulation [10, 39]. As expected, CD40 stimulation alone produced an increase in p-AKT (Figure 1C). In contrast, levels of PTEN were markedly decreased in the CLL cells co-cultured with CD154-expressing fibroblasts when compared to that in cells co-cultured with parental fibroblasts (Figure 1C). The analysis of pooled densitometry data showed that this decrease in PTEN was also statistically significant at $24 \mathrm{~h}$ (Figure 1E). The increase in p-AKT and decrease in PTEN following CD40 stimulation were both largely unaffected by the addition of IL-4 or IL-21 (Figure 1C-1E). Taken together, these findings clearly demonstrate that CD40 stimulation induces the activation of AKT and that this activation is associated with, and likely caused by, reduced expression of PTEN.

\section{Inhibition of bendamustine-induced cell death by CD40 stimulation is mediated by AKT}

Having shown that AKT is activated by CD40 stimulation in CLL cells, we next sought to establish whether activated AKT contributes to the cytoprotective 

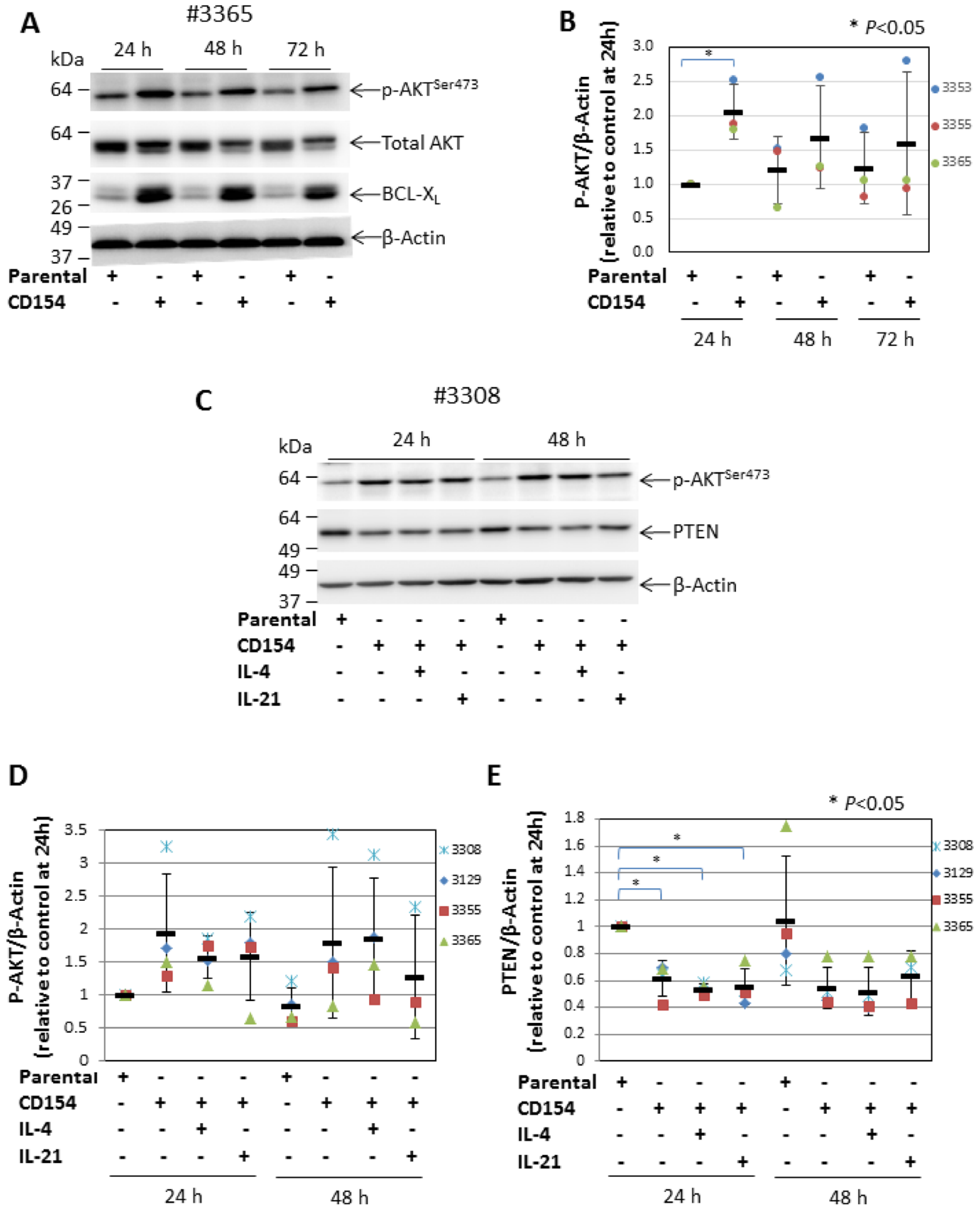

Figure 1: CD40 stimulation-induced AKT activation is associated with decreased expression of PTEN. (A) CLL cells were cultured on a monolayer of parental control or CD154-expressing fibroblasts for 24, 48 and $72 \mathrm{~h}$. At the indicated time points, CLL cells were harvested and analysed for the levels of p-AKT (serine 473) and total AKT by Western blotting. BCL- $\mathrm{X}_{\mathrm{L}}$ was probed as a marker for CD40 stimulation. $\beta$-actin was used as a loading control for densitometric analysis. One representative blot from 3 CLL samples examined is shown. (B) shows a pooled data analysis of the effect of CD40 stimulation on levels of p-AKT in co-cultured CLL cells. In this and subsequent figures, each bar represents the mean \pm SD, unless otherwise stated. (C) CLL cells were co-cultured for 24 and $48 \mathrm{~h}$ as in (A) but in the presence or absence of recombinant human IL-4 $(10 \mathrm{ng} / \mathrm{ml})$ or IL-21 $(12.5 \mathrm{ng} / \mathrm{ml})$. CLL cells were then harvested and analysed for levels of p-AKT (serine 473) and PTEN by Western blotting. One representative blot from 4 CLL samples examined is shown. (D) shows a pooled data analysis of the effect of CD40 stimulation on levels of p-AKT in co-cultured CLL cells as in (C). (E) shows a pooled data analysis of the effect of CD40 stimulation on levels of PTEN in co-cultured CLL cells as in (C). 
effect of CD40 stimulation against drug-induced killing in stimulated cells. To this end, we used a novel, selective ATP-competitive inhibitor of AKT, AZD5363 [40]. Preliminary experiments showed that the inhibitor potently inhibited AKT activity, as measured by dephosphorylation of GSK $3 \alpha / \beta$, in CLL cells after incubation for $24 \mathrm{~h}$ under standard conditions with an estimated $\mathrm{IC}_{50}$ of $3 \mu \mathrm{M}$ (Supplementary Figure $1 \mathrm{~A}$ and $1 \mathrm{~B}$ ). However, AZD5363 at concentrations up to $30 \mu \mathrm{M}$ did not induce cell death in these cells (Supplementary Figure 1C and 1D). The inhibitor also produced a concentrationdependent reduction of AKT activity in CD40-stimulated CLL cells with $10 \mu \mathrm{M}$ AZD5363 achieving greater than $50 \%$ inhibition (Supplementary Figure 2A and 2B). We therefore used AZD5363 at a concentration of $10 \mu \mathrm{M}$ for subsequent experiments. We chose the cytotoxic drug bendamustine owing to its expanding role in the treatment of previously untreated and recurrent CLL [41, 42]. CLL cells were co-cultured on monolayers of control or CD154-expressing fibroblasts in the presence or absence of bendamustine with or without the AKT inhibitor, and monitored for the induction of cell death at 24 and $48 \mathrm{~h}$. As shown in Figure 2A and 2B, CLL cells co-cultured with CD154-expressing fibroblasts had a reduced spontaneous cell death at both time points when compared with cells co-cultured with control fibroblasts. In addition, cell death induced by bendamustine at both 30 and $100 \mu \mathrm{M}$ was significantly reduced in CD40-stimulated CLL cells as compared to cells co-cultured with control fibroblasts at 24 and $48 \mathrm{~h}$ (Figure 2A and 2B). Importantly, addition of $10 \mu \mathrm{M}$ AZD5363 not only increased spontaneous cell death in cells co-cultured with CD154-expressing fibroblasts, but also restored sensitivity of CD40-stimulated CLL cells to bendamustine-induced killing to the levels seen in the CLL cells co-cultured with control fibroblasts at both time points (Figure $2 \mathrm{~A}$ and $2 \mathrm{~B}$ ). The above results clearly indicate that AKT mediates chemoresistance due to CD40 stimulation.

\section{Stimulation of CLL cells via CD40 + IL-4 or IL-21 induces cell growth that is partly dependent on AKT}

We next focused our attention on the growth and proliferation of CLL cells given the established role of AKT in regulating these processes in other cells. We first examined co-cultured CLL cells for an increase in cell size which is known to be one of the functional consequences of CD40 stimulation [43]. To do this, we used forward light scatter (FSC) obtained by flow cytometry as an indicator of cell size, as described [43]. We first compared the FSC properties of CLL cells co-cultured with CD154expressing versus parental fibroblasts in the presence of IL-4. As expected, a time-dependent increase in FSC was observed in CLL cells co-cultured with CD154-expressing fibroblasts, whereas no such increase was seen in cells co- cultured with control fibroblasts (Supplementary Figure 3A and $3 \mathrm{~B}$ ). The increase in FSC in CD40-stimulated cells was observed as early as day 1 following co-culture with CD154-expressing fibroblasts and continued to increase over the next 3 days (Supplementary Figure 3B). Similar experiments were performed with CLL cells stimulated by CD40 + IL-21 (since IL-21 induces apoptosis in CLL cells cultured in the absence of CD40 stimulation [39], the control for this experiment did not include IL-21). As with CD40 + IL-4, a similar time-dependent increase in FSC was observed in CD40 + IL-21-stimulated cells, whereas no such increase was observed in CLL cells co-cultured with control fibroblasts alone (Supplementary Figures 3C and 3D). Again, the increase in cell size was statistically significant on day 1 following co-culture with CD154expressing fibroblasts and increased further over the next 3 days (Supplementary Figure 3D).

To determine whether the increased size of CLL cells induced by CD40 stimulation was mediated by AKT, co-cultured CLL cells were again treated with the AKT inhibitor AZD5363. As shown in Supplementary Figure 3E, AZD5363 significantly reduced the increase in cell size due to stimulation by CD154 plus IL-4, although not to the background levels seen in cells co-cultured with control fibroblasts. Similar levels of inhibition of cell expansion by AZD5363 were also observed in CLL cells co-cultured with CD154-expressing fibroblasts in the presence of IL-21 (Supplementary Figure 3F).

To confirm the effects observed with AZD5363, we repeated the experiments using another AKT inhibitor: MK-2206. We chose MK-2206 as it inhibits AKT activity by binding to the plextrin-homology domain of the enzyme, preventing its translocation to the membrane and subsequent activation [44], thus utilising a mode of action different to that of AZD5363. MK-2206 has also been shown to induce apoptosis in CLL cells in vitro, with an $\mathrm{LC}_{50}$ of $8 \mu \mathrm{M}$ after 72 hours incubation under standard culture conditions [45]. We therefore used MK-2206 at a concentration of 1,3 and $10 \mu \mathrm{M}$ in our experiments. Similar to AZD5363, MK-2206 inhibited the CD40 stimulation-induced increase in cell size in a concentration-dependent manner in all CLL samples examined (Supplementary Figure 3G). Taken together, the above results strongly suggest that increase in size of CLL cells induced by CD40 stimulation is at least in part mediated by AKT.

\section{CLL cells undergo mitosis following stimulation by CD40 in the presence of IL-4 or IL-21}

We next examined the role of AKT in CLL-cell mitosis. To do this, CLL cells pre-incubated with the supravital fluorochrome CFSE were co-cultured with CD154-expressing fibroblasts in the presence of recombinant human IL-4 or IL21. Proliferation was detected as a reduction in fluorescence intensity due to CFSE as described previously [39]. 
CFSE-labelled CLL cells were also co-cultured with parental fibroblasts as a negative control. As shown in Figure 3A, CLL-cell proliferation was more rapid, pronounced and consistent following stimulation with CD154 + IL-21 as compared with CD154 + IL-4 (Figure 3A). To establish the identity of the divided cells, aliquots of cells harvested at the indicated time points were tested for expression of CD5 and
CD19. As shown in Supplementary Figure 4, most of the cells with reduced CFSE fluorescence intensity were shown to be double positive for both CD5 and CD19, confirming that these divided cells were indeed CLL cells.

Quantitative analysis of the percentage of divided cells in the time-course experiments confirmed that CD154 + IL-21 was more potent than CD154 + IL-4 in

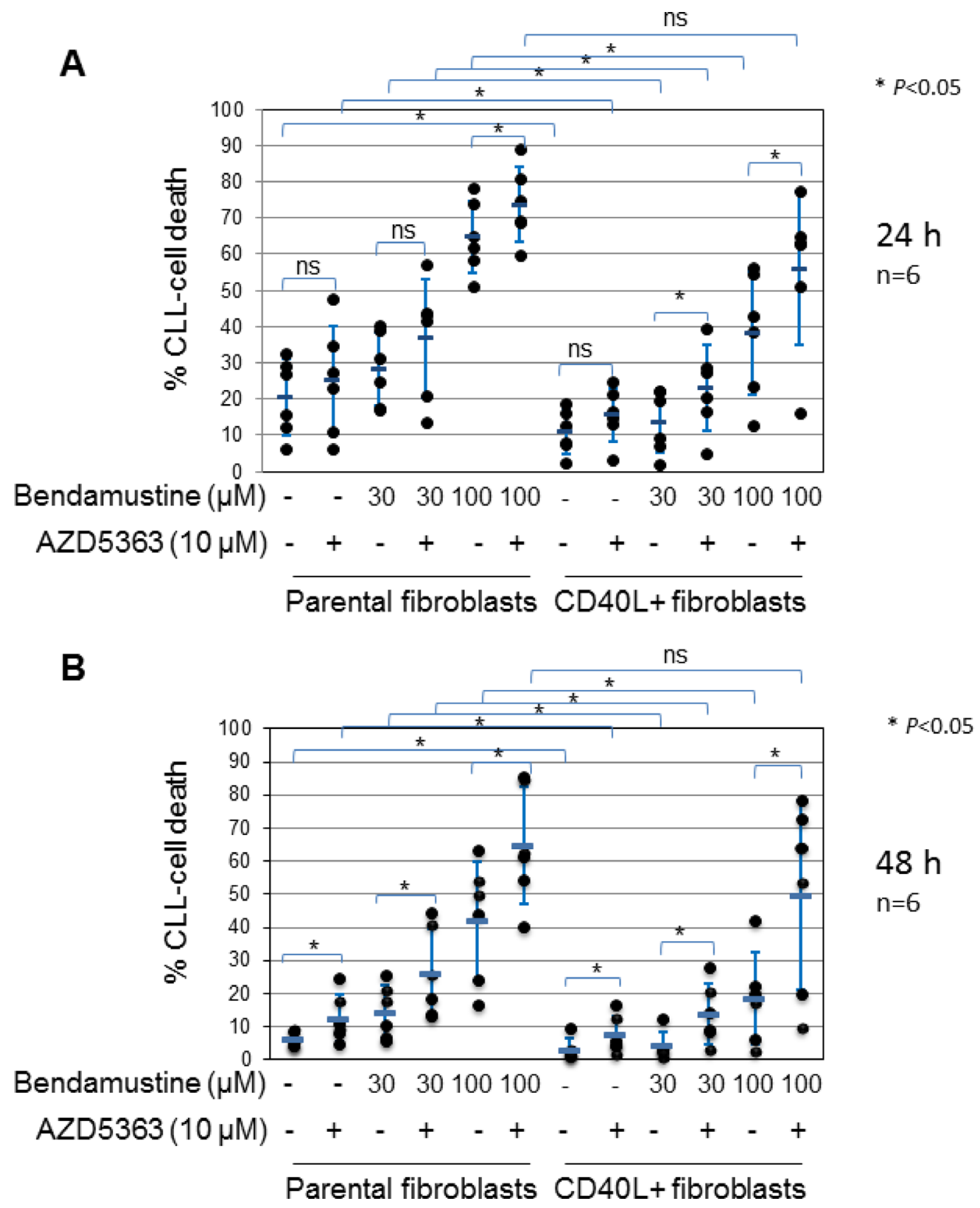

Figure 2: AKT is required for CD40 stimulation-mediated survival and inhibition of bendamustine-induced cell death. CLL cells were cultured on a monolayer of control or CD154-expressing fibroblasts in the presence or absence of bendamustine at the indicated concentration with or without AZD5363 $(10 \mu \mathrm{M})$ for $24 \mathrm{~h}(\mathbf{A})$ and $48 \mathrm{~h}(\mathbf{B})$. Co-cultured CLL cells were then harvested at the indicated time points and cell death was determined by PI inclusion on flow cytometry as described in Method. Each data set represents mean \pm SD from 6 independent experiments using CLL cells from 4 different patients. Also actual data from individual CLL samples are shown in filled dot. 
inducing CLL-cell mitosis in terms of both magnitude and speed (Figure 3B). Thus, CD154 + IL-21 produced a significantly higher percentage of divided cells, with a significant difference seen as early as day 5 and persisting for at least 9 days (Figure 3B).

\section{AKT contributes to mitosis induced by CD40 + IL-4}

Next, we examined the role of AKT in CLLcell proliferation induced by CD154 + IL-4. To do this, we again used AZD5363 at $10 \mu \mathrm{M}$. As shown

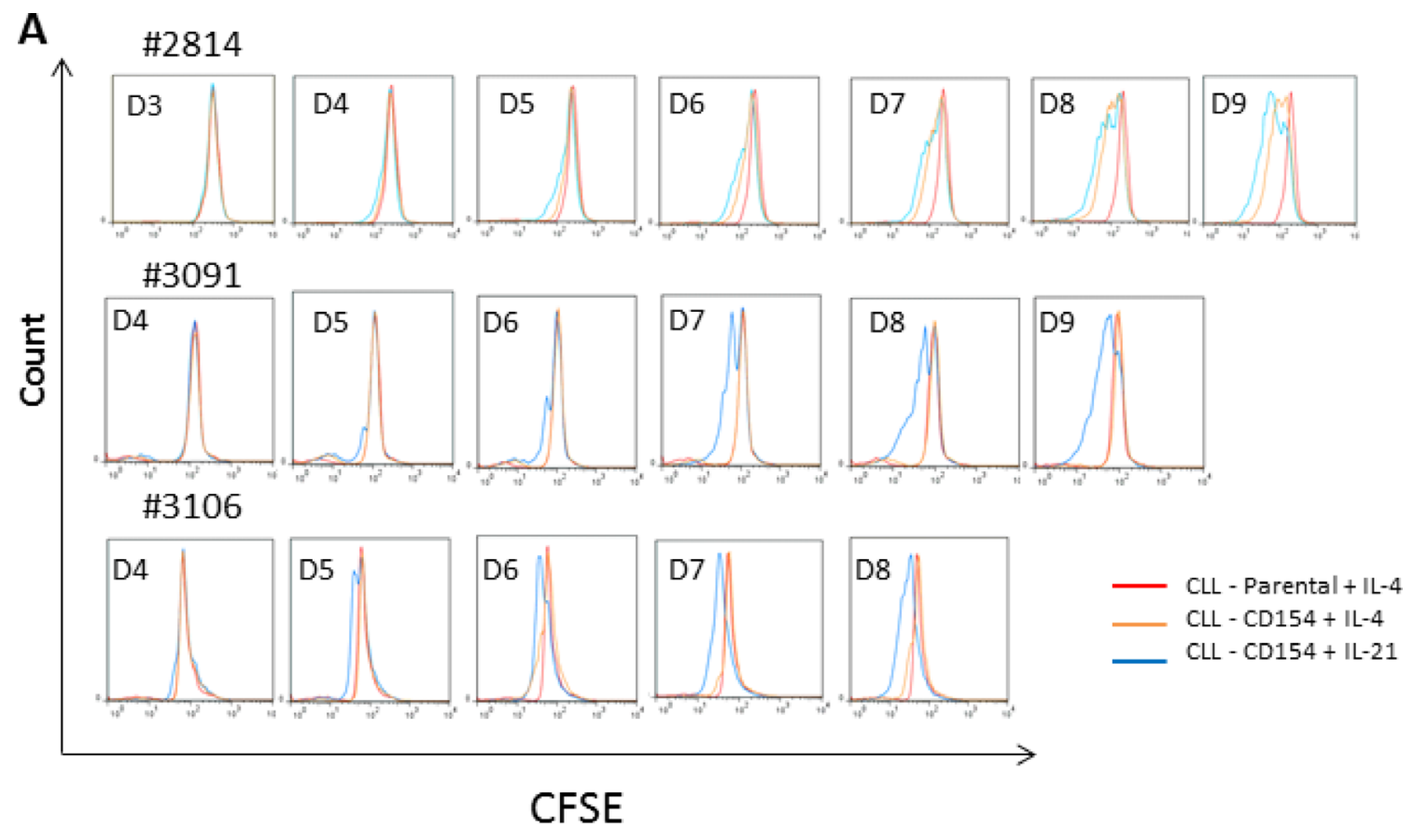

B

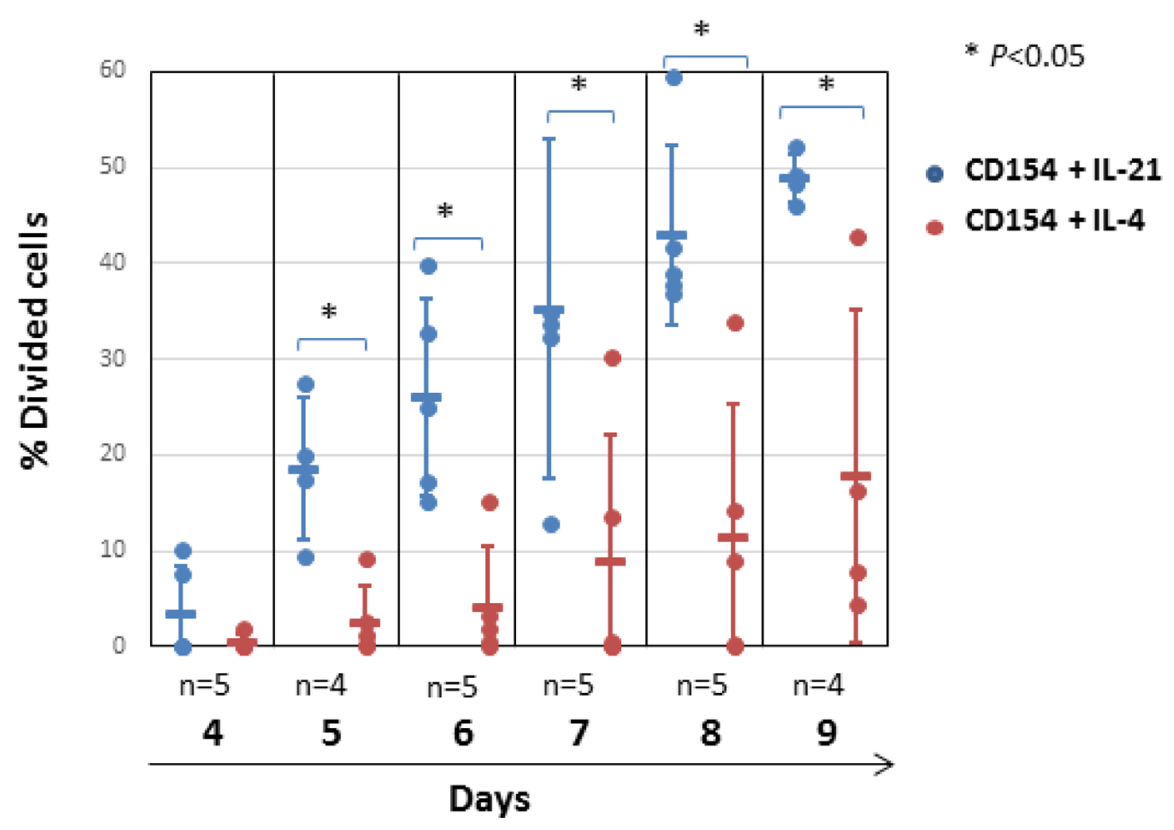

Figure 3: Stimulation by CD154 + IL-21 is more potent than that of CD154 + IL-4 in inducing proliferation of CLL cells in vitro. (A) CFSE labelled CLL cells were co-cultured with CD154-expressing fibroblasts in the presence of recombinant human IL-4 $(10 \mathrm{ng} / \mathrm{ml})$ or IL-21 $(12.5 \mathrm{ng} / \mathrm{ml})$ over a period of up to ten days. CFSE labelled CLL cells co-cultured with parental fibroblasts were used as a negative control. At the indicated time points, co-cultured CLL cells were harvested and proliferation was measured by reduction of CFSE fluorescence intensity on flow cytometry as described in Method. Three representative CFSE histograms from the time-course experiments using primary CLL cells from 5 different samples are shown. (B) Pooled data analysis of the divided cell population among CLL cells co-cultured as in (A) shows that stimulation of CD40 + IL-21 induced significantly higher percentage of divided cells than that of CD40 + IL-4. Percentage of divided cells was calculated using FlowJo software as described in Method. 
in Figure 4A, treatment of the stimulated CLL cells with AZD5363 significantly inhibited the loss of fluorescence due to CFSE, indicating that AKT contributes to mitosis induced by CD154 + IL-4. This was confirmed by quantitative analysis (Figure 4B). Importantly, AZD5363 had no effect on the viability of CLL cells stimulated by CD154 + IL-4 (Figure 4C). This observation indicates that the anti-mitotic effect of AZD5363 was specific and not simply the consequence of cytotoxicity. It also suggests that IL-4 can overcome the pro-death effects of AKT inhibition in the CD154 co-culture system.

\section{AKT contributes to mitosis induced by CD40 + IL-21 in most but not all cases}

We then investigated the role of AKT in CLL-cell proliferation induced by CD154 + IL-21 using a similar approach, but employing a range of concentrations of the inhibitor. In contrast to the results obtained with CD154 + IL-4, pooled analysis of eight CLL samples stimulated with CD154 + IL-21 failed to show any significant changes in the percentage of divided cells as a result of AKT inhibition with AZD5363 $(P>0.05)$. However, analysis of individual patient samples showed that the AKT

A $\quad \# 2814$
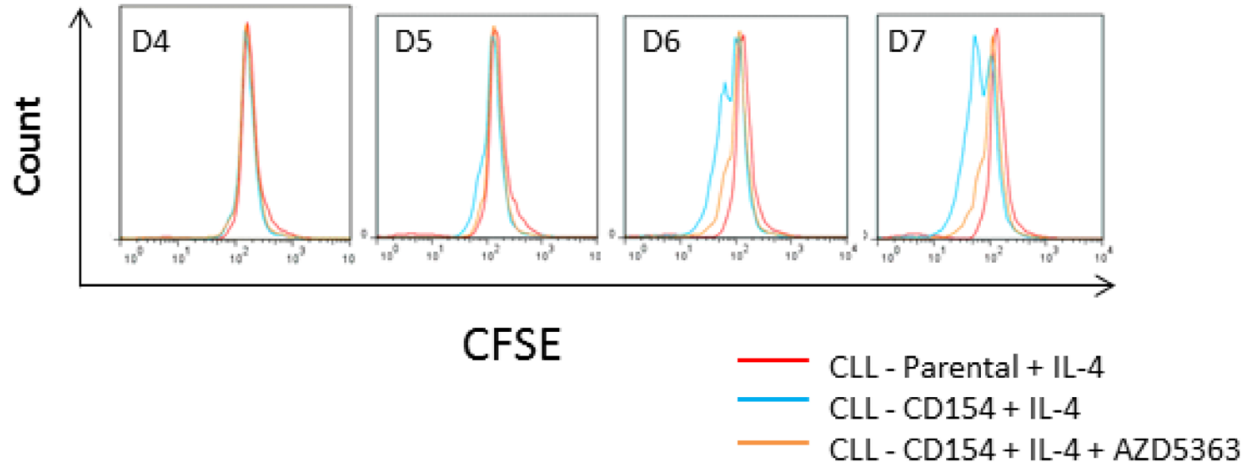

B

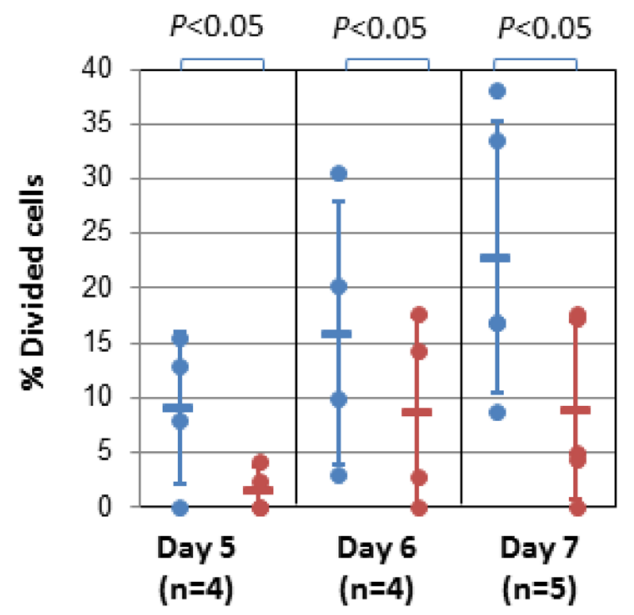

CD154 + IL-4

CD154 + IL-4 + AZD5363

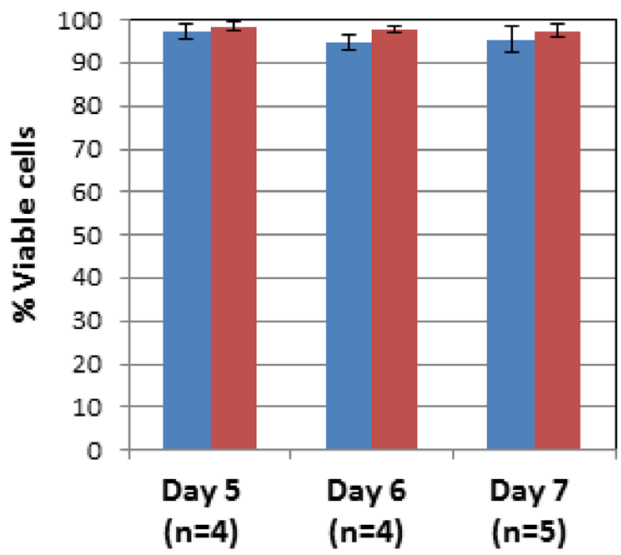

Figure 4: AKT is required for proliferation induced by CD154 + IL-4. (A) CFSE labelled CLL cells were co-cultured with CD154-expressing fibroblasts in the presence of recombinant human IL-4 (10 ng/ml) in the presence or absence of AKT inhibitor AZD5363 $(10 \mu \mathrm{M})$ over a period of 7 days. CFSE labelled CLL cells co-cultured with parental control fibroblasts were used as a negative control. At the indicated time points, co-cultured CLL cells were harvested and measured for reduction of CFSE fluorescence intensity by flow cytometry as in Figure 3A. Representative CFSE histograms of co-cultured CLL cells between 4 and 7 days from one of the five patient samples are shown. (B) Pooled data analysis of \% divided cells among co-cultured CLL cells shows that addition of AZD5363 (10 $\mu$ M) significantly reduced \% divided cells in CD40 + IL-4-stimulated CLL cells. (C) Viability of co-cultured CLL cells as in (B) was determined by PI exclusion/flow cytometry method as described in Method. Pooled data analysis shows that $10 \mu$ M AZD5363 had no effect on cell viability of co-cultured cells. 
inhibitor reduced the percentage of divided CLL cells in a concentration-dependent manner in six out of the eight cases (Figure 5A, blue symbols). AZD5363 at $10 \mu \mathrm{M}$ concentration has significantly reduced the percentage of proliferating CLL cells in these samples at days 5, 6,7 and $8(P<0.05$, Figure 5A). In contrast, AZD5363 failed to inhibit proliferation induced by CD154 + IL-21 in two other CLL samples (Figure 5A, red symbols). In the case of sample 3355, the AKT inhibitor further increased proliferation induced by CD154 + IL-21. AZD5363 at these concentrations did not induce cell death in CLL cells from all patient samples (Figure 5B), indicating that its effect on proliferation was selective and not due to cytotoxicity. It also suggests that IL-21 can overcome the pro-death effects of AKT inhibition in the CD154 co-culture system.

To confirm the anti-proliferative effects of AZD5363, the above experiments were repeated using MK-2206 at concentrations of 1,3 and $10 \mu \mathrm{M}$. In the six samples where proliferation was inhibited by AZD5363, MK-2206 produced a concentration-dependent inhibition of CLLcell mitosis induced by CD154 + IL-21 (Supplementary Figure 5A, blue symbols). MK-2206 at concentrations of 1 and $3 \mu \mathrm{M}$ had no effect on cell viability at these concentrations (Supplementary Figure 5B). Similarly, in the two samples where proliferation was not inhibited by AZD5363, MK-2206 at concentrations of 1 and $3 \mu \mathrm{M}$ did not significantly inhibit CLL-cell mitosis induced by CD154 + IL-21 (Supplementary Figure 5A, red symbols). When MK-2206 was used at a concentration of $10 \mu \mathrm{M}$, a reduction in the percentage of divided cells was observed (Supplementary Figure 5A). However, this corresponded to a reduction in viability (Supplementary Figure 5B). MK2206 at $10 \mu \mathrm{M}$ reduced the viability particularly in the two samples where proliferation was not inhibited by AZD5363 and MK-2206 at 1 and $3 \mu \mathrm{M}$ concentrations, with an average viability of $51 \%$ at day $5,50 \%$ at day $6,24 \%$ at day 7 and $23 \%$ at day 8 , respectively. This indicates a cytotoxic effect of the inhibitor at this concentration. Taken together, the two AKT inhibitors with different modes of action produced similar effects on CLL-cell mitosis induced by CD154 + IL-21, both inhibiting proliferation in the same six patient samples but not inhibiting such proliferation in the two other samples.

\section{AKT inhibition in CD40 + IL-21-stimulated cells is associated with repression of cyclin $\mathrm{A} 2$ and CDK1}

In an attempt to identify molecules involved in the anti-proliferative effect of AKT inhibition, the same CLL samples were co-cultured with CD154-expressing fibroblasts in the presence of IL-21 with or without AZD5363 $(10 \mu \mathrm{M})$ for $24 \mathrm{~h}, 48 \mathrm{~h}$ and $72 \mathrm{~h}$ and analysed by Western blotting for the expression of key molecules involved in cell-cycle regulation. The results were compared between cases that were responsive or unresponsive to the anti-proliferative effects of AKT inhibition. CLL cells cocultured with the parental fibroblasts were used as a control. First, we compared the expression of cyclins (e.g. A2, D2, D3, E1) and negative regulators of cyclin-dependent kinases (including p27 and p21).

In keeping with previous reports [46, 47], unstimulated CLL cells expressed higher levels of p27 (Figure 6A, lane 1). Levels of p27 were reduced following co-culture with parental control fibroblasts (Figure 6A lanes 2-4) and decreased further following co-culture with CD154-expressing fibroblasts + IL-21 (Figure 6A, lanes 5-7). We also examined the expression of p21 but failed to detect it in unstimulated CLL cells (Figure 6A, lanes 1-4), although it was detected at low levels in CLL cells cocultured on CD154-expressing fibroblasts (Figure 6A, lanes 5-7). Addition of AZD5363 restored the expression of $\mathrm{p} 27$ but had little effect on the expression of p21 (Figure 6A, lanes 8-10). There was no difference in the expression of p27 and p21 or in the effect of AZD5363 on this expression between CLL samples that were responsive or unresponsive to the anti-proliferative effects of AKT inhibition.

As expected, unstimulated CLL cells expressed hardly any cyclins (Figure 6A, lane 1). Co-culture with control fibroblasts induced the expression of cyclins D2 and D3, but not cyclins A2 and E1 (Figure 6A, lanes 2-4). However, cyclins A2 and E1 were upregulated following stimulation by CD154 + IL-21 (Figure 6A, lanes 5-7). Interestingly, addition of AZD5363 consistently inhibited induction of cyclin A2, but not cyclin E1 in all the samples examined (Figure 6A, lanes 8-10). Pooled data analysis showed that inhibition of cyclin A2 expression by AZD5363 was statistically significant (Figure 6B). There was again no difference in the expression of cyclins or in the effect of AZD5363 on this expression between CLL samples that were responsive or unresponsive to the antiproliferative effects of AKT inhibition.

Next, we compared expression of cyclin-dependent kinases (CDKs) 1, 2 and 4 in these CLL cells. As shown in Figure 6C (lane 1), unstimulated CLL cells expressed very little amount of these CDKs. CDK2 expression was increased in CLL cells co-cultured with parental fibroblasts, but unaffected by CD40 stimulation (Figure 6B, compare lanes 5-7 to lanes 2-4) or AZD5363 (Figure 6C, lanes 8-10). CDK4 was induced in CLL cells following stimulation by CD154 + IL-21 (Figure 6C, lanes 5-7), as was CDK1 (Figure 6C, lane 7). However, compared to CDK4, induction of CDK1 appeared to be delayed as it was only detected on day 3 in all the CLL samples examined (Figure 6C, lane 7). CDK1 induction was consistently inhibited by AZD5363 (Figure 6C, lane 10), although pooled data analysis failed to show statistical significance (Figure 6D). Again, there was no difference in the expression of CDKs or in the effect of AZD5363 on this expression between CLL samples that were responsive or unresponsive to the anti-proliferative effects of AKT inhibition. 


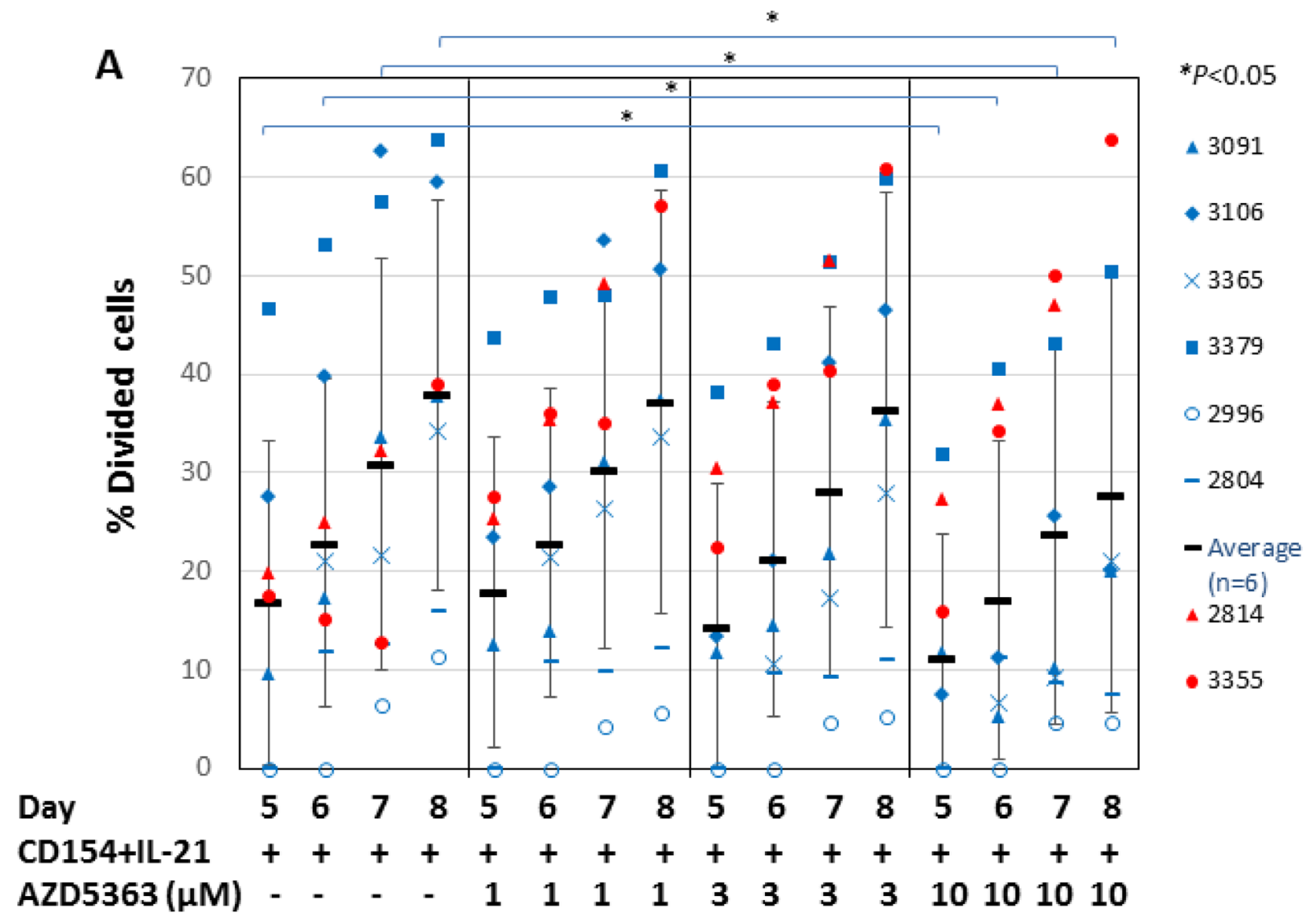

B

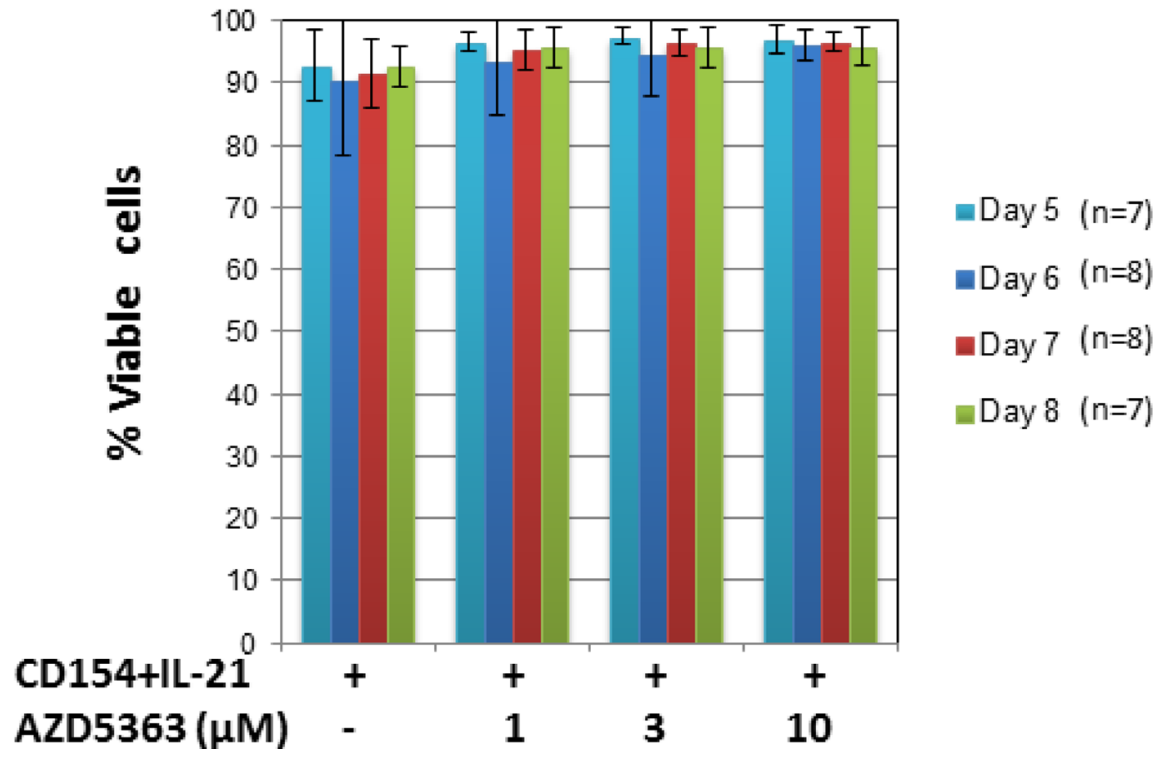

Figure 5: AKT is only required for CD154 + IL-21-induced proliferation in CLL cells from most, but not all patients. (A) CFSE labelled CLL cells were co-cultured with CD154-expressing fibroblasts in the presence of recombinant human IL-21 $(12.5 \mathrm{ng} / \mathrm{ml})$ in the presence or absence of AZD5363 at the indicated concentrations over a period of 8 days. At the indicated time points, co-cultured CLL cells from eight individual patient samples were harvested and measured for reduction of CFSE fluorescence intensity by flow cytometry as in Figure 3A. Percentage of divided cells was calculated as in Figure 3B. Data from samples that were responsive to inhibition of proliferation by AZD5363 as indicated by blue symbols is represented by mean \pm SD from independent experiments using CLL cells from six different patients. Data from samples where proliferation was not inhibited by AZD5363 is indicated with red symbols. (B) Viability of co-cultured CLL cells as in (A) was determined as in Figure 4C. Pooled data analysis shows that AZD5363 at the indicated concentrations had no effect on cell viability of co-cultured cells as described in (A). 
In summary, co-culture of CLL cells with control fibroblasts reduced p27 expression and increased the expression of cyclin D2, cyclin D3 and CDK2. Stimulation with CD154 + IL-21 further reduced the expression of p27 and increased the expression of p21, cyclin A2, cyclin E1,
CDK1 and CDK4. AZD5363 inhibited some of these effects (p27 repression and induction of p21, cyclin A2, cyclin D2, cyclin D3 and CDK1) but not others (induction of cyclin E1, CDK2 and CDK4). Importantly, no differences were observed in the expression of any of these proteins or in

\section{A $\# 3365$}

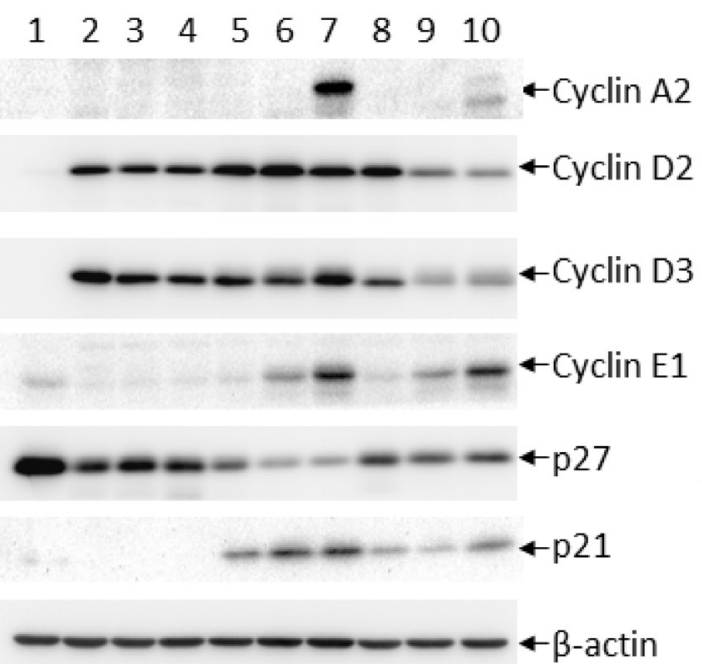

Time (d) $0 \begin{array}{llllllllll}0 & 1 & 2 & 3 & 1 & 2 & 3 & 1 & 2 & 3\end{array}$

$\overline{\text { Parental }} \overline{\mathrm{CD} 154}+\overline{\mathrm{CD} 154+}$

IL-21 IL-21+

AZD5363

\section{C $\# 3355$}

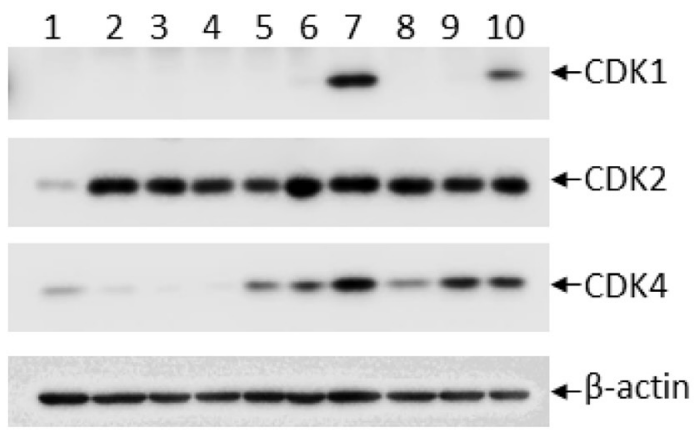

Time (d) $\begin{array}{llllllllll}0 & 1 & 2 & 3 & 1 & 2 & 3 & 1 & 2 & 3\end{array}$

Parental CD154+ CD154+

IL-21 IL-21+

AZD5363
B

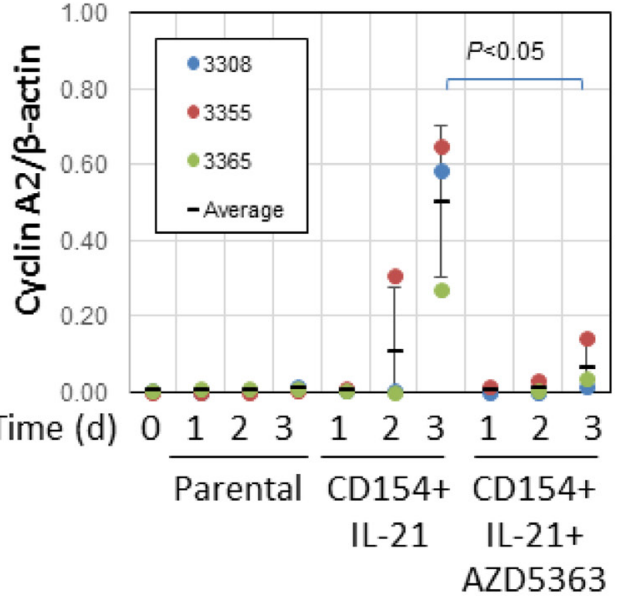

D

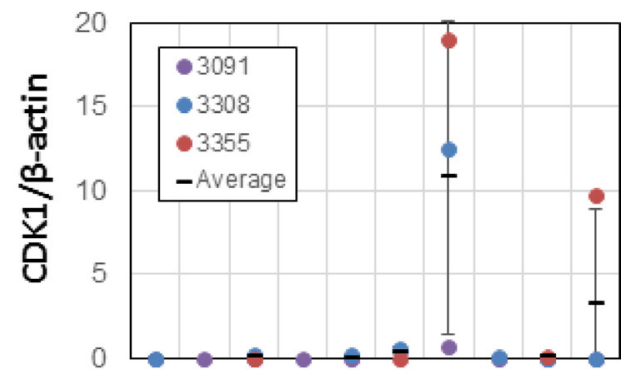

Time (d)

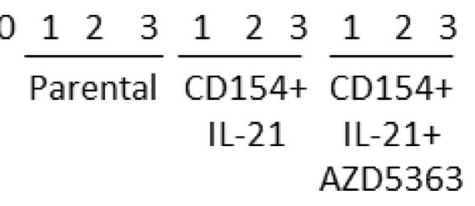

Figure 6: AKT is required for the induction of cyclin A2 and CDK1 by CD40 + IL-21 stimulation. (A) CLL cells were cultured on a monolayer of control or CD154-expressing fibroblasts in the presence of recombinant human IL-21 (12.5 ng/ml) over a period of 3 days with or without $10 \mu \mathrm{M}$ AZD5363. At the indicated time points, CLL cells were harvested and analysed for levels of cyclins A2, D2, D3 and E1, and p27 and p21 by Western blotting. $\beta$-actin was used as a loading control for densitometric analysis. One representative set of blots from the three of the 5 CLL samples described in Figure 5A is shown. (B) shows a pooled data analysis of the effect of AZD5363 on level of cyclin A2 in the co-cultured CLL cells as in (A). (C) CLL cells co-cultured under conditions as in (A) were harvested and analysed for levels of CDKs 1,2 and 4 by Western blotting. $\beta$-actin was used as a loading control for densitometric analysis. One representative set of blots from the three of the 5 CLL samples described in Figure 5A is shown. (D) shows a pooled data analysis of the effect of AZD5363 on level of CDK1 in the co-cultured CLL cells as in (C). 
the effect of AZD5363 on this expression between CLL samples that were responsive or unresponsive to the antiproliferative effects of AKT inhibition. The molecular mechanisms responsible for the variable effect of AKT inhibition on CLL-cell proliferation induced by CD154 + IL-21 therefore still remain to be elucidated.

\section{Proliferation of normal B cells induced by CD154 + IL-4 or IL-21 does not involve AKT}

Finally, to investigate whether inhibition of CD154 + IL-4 or IL-21-induced proliferation by the AKT inhibitors is selective to CLL cells, we repeated the experiment using normal B cells purified from buffy coats by negative selection using a commercially available B cell isolation kit. As shown in Figure 7A, normal B cells were readily induced to proliferate on day 3 when co-cultured with CD154expressing fibroblasts + IL-4, as indicated by the formation of a sub-peak on the CFSE fluorescence histograms (Figure 7A, blue line). In contrast to CLL cells, such proliferation in normal B cells was not inhibited by co-incubation with $10 \mu \mathrm{M}$ AZD5363 (Figure 7A, orange line). This suggests that the anti-proliferative effect of AZD5363 is relatively selective to CLL cells. Consistent with the above observation, normal B cells were also readily induced to proliferate following stimulation by CD154 + IL-21 (Figure 7B, blue line). Quantitative analysis of the data showed that significant amounts of divided cells $(36 \% \pm 25.1)$ were detected by day 4 (Figure 7D, blue dots). By day 5, \% of divided cells increased to $57.5 \%( \pm 18.2)$ (Figure 7D, red dots). The addition of $1-10$ $\mu \mathrm{M}$ AZD5363 had no effect on this proliferation (Figure $7 \mathrm{~B}$ and 7D). The same was true of $1-10 \mu \mathrm{M}$ MK-2206 (Figure 7C and 7D). Neither AZD5363 nor MK-2206 at the concentrations used in the study induced significant amounts of cell death in stimulated normal B cells (Figure 7E). Collectively, these results suggest that AKT inhibition by AZD5363 or MK-2206 does not inhibit the proliferation of normal B cells induced by CD154 + IL-21 and that AKT is therefore not required for proliferation of normal $\mathrm{B}$ cells in response to CD40 stimulation.

\section{DISCUSSION}

This study was conducted to determine whether AKT plays a role in CD40 stimulation-mediated cell survival, growth and proliferation of CLL cells and, in doing so, further elucidate the role of AKT in CLL biology. We confirmed previous reports that CD40 stimulation induces activation of AKT in CLL cells [21, 35, 36]. We also showed that this activation was associated with decreased expression of PTEN, a result consistent with a recent report that CD40 stimulation results in a specific induction of microRNA-22, a cellular inhibitor of PTEN, which subsequently leads to AKT activation in CLL cells [48].

To address the extent to which AKT mediates the pro-survival effect of CD40 stimulation, we co- cultured CLL cells on a monolayer of CD154-expressing fibroblasts and compared their viability to that in cells cocultured with control fibroblasts. Our demonstration that CD40-stimulated CLL cells underwent less spontaneous cell death and were more resistant to bendamustineinduced killing confirms that CD154 on the surface of the transfected fibroblasts was engaging with CD40 on the CLL cells to generate pro-survival signals. Furthermore, our observations that pharmacological inhibition of AKT reduced the survival of the stimulated CLL cells and sensitized them to killing by bendamustine strongly implicates AKT as an important mediator of CD40-derived pro-survival signals.

We have also shown for the first time that AKT is required for CD40-induced cell growth as measured by an increase in the size of stimulated CLL cells. This is not unexpected since AKT is known to regulate growth and cell size via mTOR and its downstream targets S6K1 and 4EBP1/eIF4E [49], and by stimulating protein synthesis and inhibiting protein degradation [50]. It has also been shown that AKT maintains cell size and survival by increasing mTOR-dependent nutrient uptake, which is required for protein synthesis [51].

Regarding the variation in kinetics of proliferation observed in our co-culture system between CLL cells and normal B cells and between different cases of CLL, our results are entirely in agreement with in vivo studies showing that normal B cells proliferate more rapidly (1.5-4.24\% per day) $[52,53]$ than CLL cells $(0.08-1.7 \%$ per day) $[53,54]$ and that proliferation kinetics vary widely between different cases of CLL $[53,55]$. Importantly, pharmacological inhibition of AKT inhibited the proliferation of CLL cells in most cases irrespective of the rate of mitosis but had no effect on the proliferation of normal B cells. This observation suggests that AKT plays a more prominent role in signalling proliferation induced by CD40 + IL-4 or IL-21 in CLL cells as compared with B cells.

Our data suggest that the role of AKT in CLL-cell proliferation induced via CD40 is both stimulus and case dependent. The pronounced and consistent inhibitory effect of AKT inhibition on CLL-cell proliferation induced by CD154 + IL-4 implies a crucial role for AKT in signalling mitosis in CLL cells under such conditions. This is entirely in keeping with a recent report demonstrating a key role of the PI3K/AKT pathway in CLL-cell proliferation induced by CD154 + IL-4 [48]. It is also in agreement with a previous report implicating AKT as a mediator of proliferation following stimulation of CLL cells with CpGoligodeoxynucleotides [56]. In contrast to results obtained with CD40 + IL-4, when CLL cells were stimulated to proliferate by CD154 + IL-21, pharmacological inhibition of AKT reduced proliferation in most but not all patient samples indicating an inconsistent role for AKT in signalling proliferation under these circumstances. A recent report that the JAK inhibitor (ruxolitinib) almost completely inhibited CLL-cell proliferation induced by CD154 + IL-21 


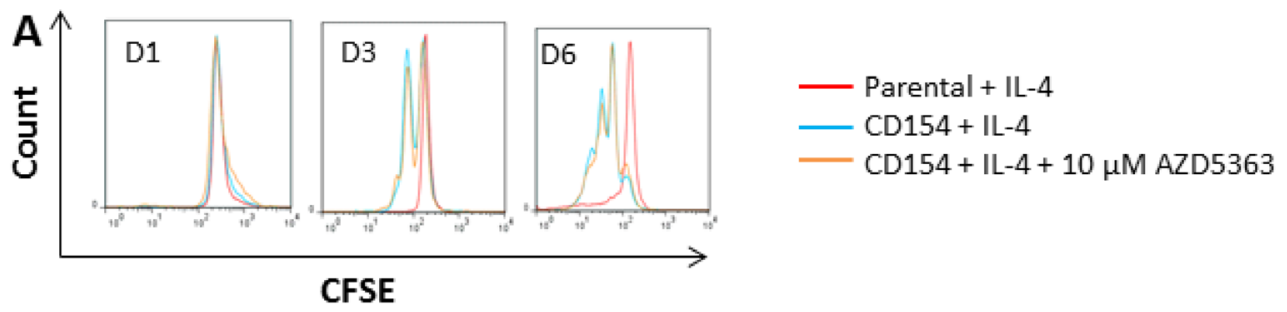

B

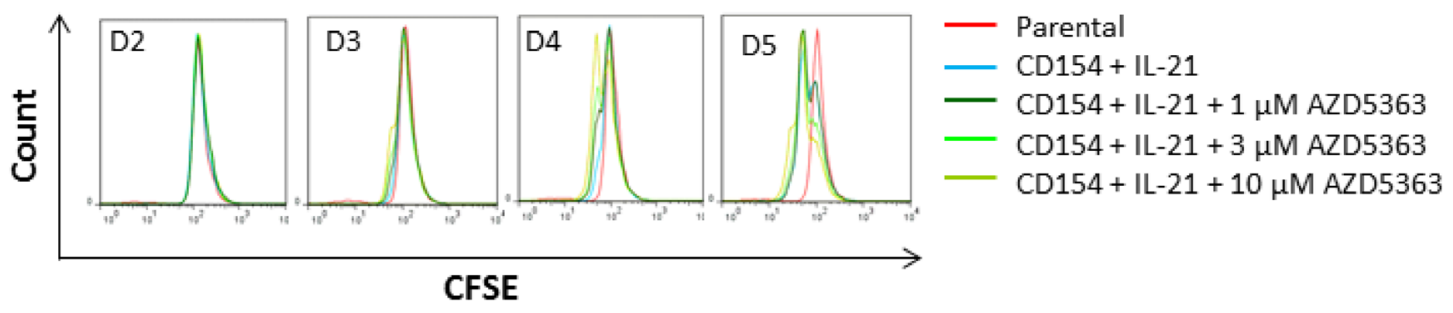

C

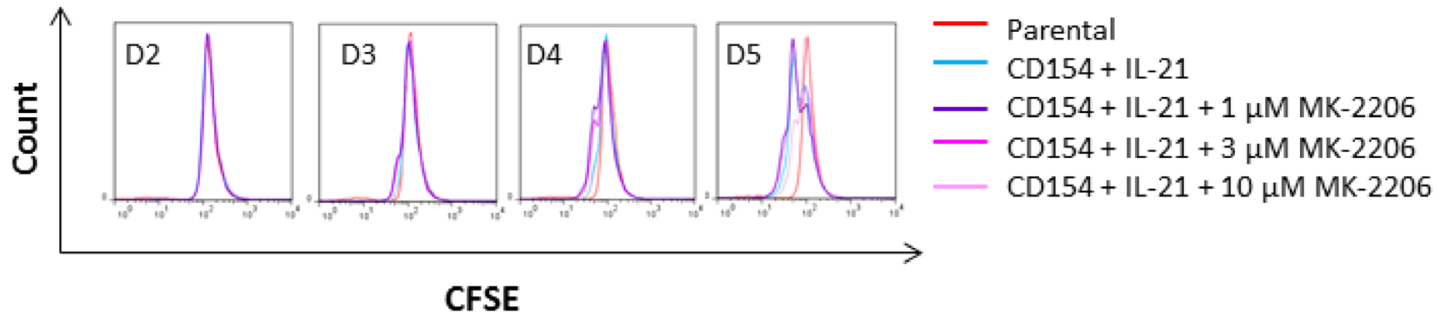

D

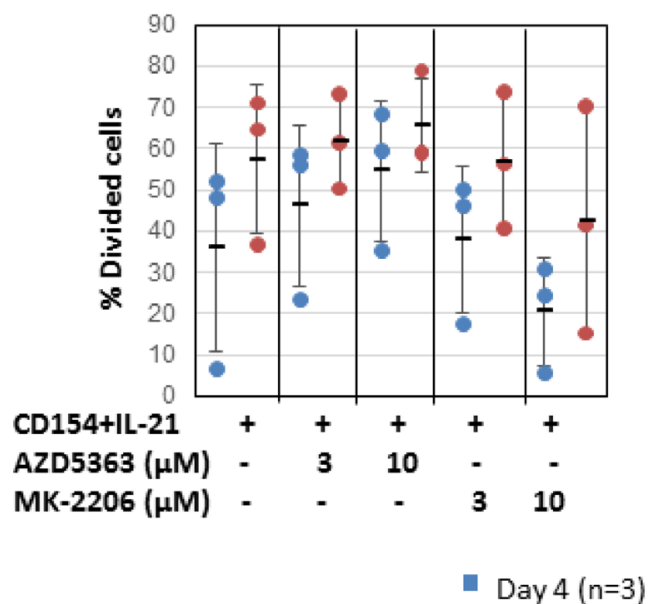

$\mathrm{E}$

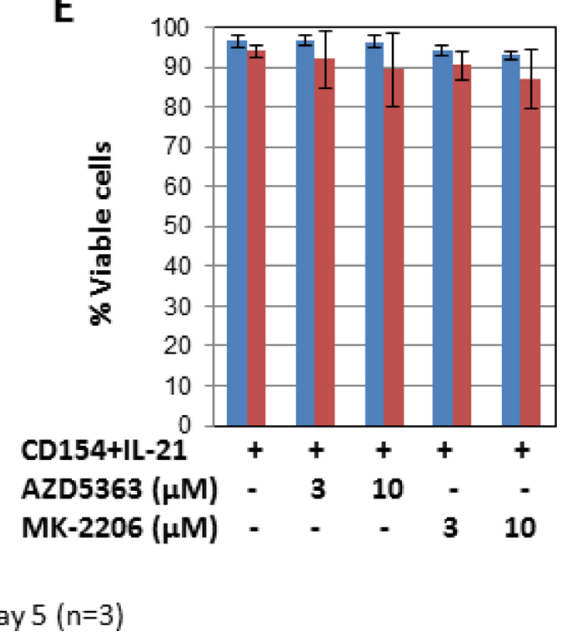

Figure 7: CD40 stimulation-induced proliferation in normal B cells does not require AKT. (A) CFSE labelled normal B cells were co-cultured with CD154-expressing fibroblasts in the presence of recombinant human IL-4 (10 ng/ml) over a period of six days with or without AZD5363 $(10 \mu \mathrm{M})$. CFSE labelled normal B cells co-cultured with parental fibroblasts plus IL-4 were used as a negative control. At the indicated time points, co-cultured B cells were harvested and proliferation was measured as in Figure 3A. One set of representative CFSE histograms from the time-course experiments using three individual normal B cell samples is shown. (B) CFSE labelled normal B cells were co-cultured with CD154-expressing fibroblasts in the presence of recombinant human IL-21 $(12.5 \mathrm{ng} / \mathrm{ml})$ over a period of five days with or without AZD5363 at the indicated concentrations. At the indicated time points, co-cultured B cells were harvested and proliferation was measured as in (A). One set of representative CFSE histograms from three different normal B cell samples examined is shown. (C) CFSE labelled normal B cells were co-cultured with CD154-expressing fibroblasts in the presence of recombinant human IL-21 $(12.5 \mathrm{ng} / \mathrm{ml})$ over a period of five days with or without MK-2206 at the indicated concentrations. At the indicated time points, co-cultured B cells were harvested and proliferation was measured as in (A). One set of representative CFSE histograms from three different normal B cell samples examined is shown. (D) Pooled data analysis shows that neither AZD5363 nor MK-2206 at the indicated concentrations inhibited CD154 + IL-21-induced proliferation in normal B cells. (E) Pooled data analysis on the viability of the co-cultured normal B cells as described in (D) shows that neither AZD5363 nor MK-2206 at the indicated concentrations adversely affected the viability of the co-cultured normal B cells. 
[39], suggests that the JAK-STAT pathway may dominate over AKT in transmitting proliferation signals under these circumstances.

In order to identify the molecules responsible for mediating the differential effect of AKT inhibition on proliferation induced by CD40 + IL-21, we compared changes in the expression of cell cycle regulatory molecules following stimulation of CLL with CD154 + IL-21 in the presence or absence of AKT inhibitors. It has recently been shown that lenalidomide inhibits CLLcell proliferation induced by CD154 + IL-4 + IL-10 in a cereblon/p21-dependent manner but independently of p53 [57]. It is also known that levels of p21 protein can be negatively modulated by AKT through direct or indirect phosphorylation [24-26]. As a result, CDKs are liberated and allowed to restore their kinase function in cell cycle progression. We therefore speculated that the differential effect of AKT inhibition on CD40 + IL-21induced proliferation could be mediated via differential induction of $\mathrm{p} 21$. However, we were unable to detect p21 expression in unstimulated CLL cells and could only detect it at low levels following stimulation with CD154 + IL-21. Importantly, AKT inhibition had little effect on the expression of p21 in all the samples examined. Instead, we found that AKT inhibition reduced the expression of cyclin A2 and CDK1 consistently in all the samples examined irrespective of whether their proliferation was inhibited or not. Therefore, the molecular mechanisms underlying the variable effect of AKT inhibition on CLL-cell proliferation induced by CD40 + IL-21 remain to be elucidated.

In summary, we have shown that AKT is an important mediator of CLL-cell survival, growth and chemoresistance induced by CD40 stimulation. We also showed that $\mathrm{AKT}$ is required for proliferation of CLL cells in response to CD154 + IL-4 and contributes to proliferation induced by CD154 + IL-21 in CLL cells in most patient samples. From a clinical perspective, the sensitisation of CLL cells to killing by bendamustine that was observed when the AKT inhibitor was added to the CD154 co-culture system provides a strong rationale for combining AKT inhibitors with chemotherapy-based treatment in order to augment cytoreduction at sites of tissue involvement. Furthermore, the anti-proliferative effect of AKT inhibition suggests that AKT inhibitors might delay re-growth of the residual leukemic clone in most patients as post-induction maintenance therapy.

\section{MATERIALS AND METHODS}

\section{CLL cell and normal B cell preparation}

Peripheral blood samples from CLL patients were obtained with informed consent and the approval of the Liverpool Research and Ethics Committee. The clinical details of the patients included for this study are given in Table 1. CLL cells were isolated by centrifugation of blood over Lymphoprep (Axis-Shield PoC AS, Oslo, Norway) and stored in a $-150^{\circ} \mathrm{C}$ freezer prior to use. Normal B cells were purified by negative selection using a B cell isolation kit (Miltenyi Biotech, Bisley, UK) from Buffy coats obtained from the National Blood Service (Liverpool, UK). B-cell purity was determined by CD19 staining and flow cytometry.

\section{Chemicals, antibodies and other reagents}

AKT inhibitor AZD5363 was provided by AstraZeneca (London, UK). Another AKT inhibitor MK-2206 was purchased from Selleck Chemical (via Stratech Scientific Ltd., Suffolk, UK). Bendamustine hydrochloride hydrate was obtained from Sigma-Aldrich (Gillingham, UK). Rabbit monoclonal antibodies against phospho-AKT (Ser473) (clone D9E), phospho-GSK-3 $\alpha / \beta$ (Ser21/9) (clone D17D2), CDK2 (clone 78B2), CDK4 (clone D9G3E), Cyclin D2 (clone D52F9), p21 (DCS60) and p27 (D69C12), and mouse monoclonal antibodies to CDK1 (clone POH1), Cyclin A2 (clone BF683), Cyclin D3 (clone DCS22), Cyclin E1 (clone HE12), and rabbit polyclonal antibodies to total AKT, BCL-XL and PTEN were all obtained from Cell Signalling Technology (via New England Biolabs, Herts, UK). Mouse monoclonal antibody to GSK $3 \alpha / \beta$ (clone $21 \mathrm{~A}$ ) was obtained from Life Technologies (Paisley, UK). Mouse monoclonal antibody to $\beta$-actin (clone AC-74) was from Sigma-Aldrich. Secondary antibodies, goat anti-mouse IgG-HRP and goat anti-rabbit IgG-HRP were from Santa Cruz Biotechnology (Insight Biotechnology, Middlesex, UK). Other chemicals, unless otherwise stated, were all obtained from SigmaAldrich.

\section{Co-culture of CLL cells}

Stably transfected mouse fibroblasts expressing human CD154 and control parental fibroblasts (both kindly provided by Professor Gerald Cohen at University of Liverpool) were maintained as described [34]. After thawing, CLL cells were maintained in RPMI 1640 medium supplemented with $10 \%$ heat-inactivated fetal bovine serum, $2 \mathrm{mM}$ L-glutamine, $100 \mathrm{U} / \mathrm{ml}$ penicillin, and $100 \mu \mathrm{g} / \mathrm{ml}$ streptomycin (Life Technologies). For CD40 stimulation, CLL cells were seeded on an adherent monolayer of CD154-expressing or control fibroblasts at a ratio of $10: 1$ and incubated at $37^{\circ} \mathrm{C}$ for an appropriate period of time, as described [34]. To determine the effects of bendamustine and AZD5363 on cell survival following CD40 stimulation, CLL cells were co-cultured for $24 \mathrm{~h}$ or $48 \mathrm{~h}$ with the CD154-expressing or parental fibroblasts in the presence or absence of the above drugs before harvesting. To induce proliferation and determine the effect of AKT inhibition on proliferation, CLL cells were co-cultured with CD154-expressing fibroblasts in the presence of recombinant human interleukin-4 (IL-4, R\&D 
Table 1: Clinical characteristics of the CLL samples used

\begin{tabular}{|c|c|c|c|c|c|c|c|}
\hline Sample number & Sex & $\begin{array}{c}\text { Age at } \\
\text { diagnosis }\end{array}$ & $\begin{array}{l}\text { Stage } \\
\text { (Binet) }\end{array}$ & $\begin{array}{l}\text { WBC } \\
\left(10^{9} / \mathbf{l}\right)\end{array}$ & $\begin{array}{l}\text { IGHV } \\
\text { status }\end{array}$ & $\begin{array}{l}\text { Chromosomal } \\
\text { abnormalities }\end{array}$ & Prior therapy \\
\hline \#1958 & $\mathrm{f}$ & 65 & A & 215 & $\mathrm{M}$ & $13 q-$ & $\mathrm{Y}$ \\
\hline \#2064 & $\mathrm{m}$ & 46 & $\mathrm{C}$ & 120 & UM & Tri12 & Y \\
\hline \#2096 & $\mathrm{m}$ & 65 & A & 60 & M & $17 p-\& 13 q-$ & $\mathrm{N}$ \\
\hline \#2103 & $\mathrm{m}$ & 56 & A & 125 & UM & $17 p-\& 13 q-$ & $\mathrm{N}$ \\
\hline$\# 2263$ & $\mathrm{~m}$ & 65 & B & 366 & UM & $11 q-\& 13 q-$ & Y \\
\hline \#2521 & $\mathrm{f}$ & 79 & B & 74 & M & Tri12 & Y \\
\hline \#2729 & $\mathrm{m}$ & 66 & A & 37 & M & normal & $\mathrm{N}$ \\
\hline \#2804 & $\mathrm{F}$ & $\mathrm{nd}^{\#}$ & A & 39.7 & M & nd & nd \\
\hline \#2814 & $\mathrm{m}$ & 72 & A & 196 & $\mathrm{UM}$ & normal & $\mathrm{N}$ \\
\hline \#2996 & $\mathrm{m}$ & nd & nd & 169.2 & M & $13 q-$ & nd \\
\hline \#3033 & $\mathrm{m}$ & 66 & A & 41 & M & normal & $\mathrm{N}$ \\
\hline \#3058 & $\mathrm{m}$ & 69 & B & 51 & UM & normal & $\mathrm{N}$ \\
\hline \#3091 & $\mathrm{m}$ & nd & nd & 41.7 & UM & $11 \mathrm{q}-$ & nd \\
\hline \#3106 & $\mathrm{m}$ & 66 & $\mathrm{C}$ & 115 & UM & $11 q-\& 13 q-$ & nd \\
\hline \#3129 & $\mathrm{m}$ & nd & nd & 31.8 & UM & nd & nd \\
\hline \#3308 & $\mathrm{m}$ & 66 & $\mathrm{C}$ & nd & UM & nd & nd \\
\hline \#3353 & $\mathrm{f}$ & 75 & A & 72 & $\mathrm{M}$ & nd & nd \\
\hline \#3355 & $\mathrm{m}$ & 73 & B & 130 & $\mathrm{M}$ & $13 q-$ & nd \\
\hline \#3365 & $\mathrm{f}$ & nd & $\mathrm{C}$ & 253 & nd & $13 q-$ & nd \\
\hline \#3379 & $\mathrm{m}$ & 67 & B & 228.5 & UM & $17 p-$ & Y \\
\hline
\end{tabular}

"IGHV status refers to somatic mutation in IGHV gene of CLL cells as compared with the gene sequence of the nearest germ-line using $2 \%$ as a cut-off. $\mathrm{M}=$ mutated; $\mathrm{UM}=$ un-mutated.

"Prior therapy consisted of various combinations of glucocorticoid, chlorambucil, fludarabine, or fludarabine plus cyclophosphamide.

\#nd: not done/unknown

Systems, Minneapolis, MN ) or IL-21 (Life Technologies), with or without the AKT inhibitors for up to ten days.

\section{Analysis of cell death by flow cytometry}

CLL cells were co-cultured with CD154-expressing or control fibroblasts in the presence or absence of cytotoxic agents at the indicated concentrations. At the end of the incubation period, co-cultured CLL cells were harvested as described [34] and their viability was determined by propidium iodide exclusion and flow cytometry as previously described [58]. Aliquots of cells from the same experiment were analysed by Western blotting for the expression of specific proteins.

\section{Analysis of proliferation by flow cytometry}

CLL cells were first incubated at $37^{\circ} \mathrm{C}$ for 10 minutes in complete RPMI 1640 medium containing $0.5 \mu \mathrm{M}$ carboxyfluorescein diacetate succinimidyl ester dye (CFSE, Molecular Probes ${ }^{\circledR}$, Life Technologies) and then washed with fresh medium to remove excess dye. Cells were then incubated for a further 20 minutes at $37^{\circ} \mathrm{C}$ and washed again before being re-suspended in fresh medium containing recombinant human IL-4 (at $10 \mathrm{ng} / \mathrm{ml}$ ) or IL-21 (at $12.5 \mathrm{ng} / \mathrm{ml}$ ) and seeded onto an adherent monolayer of CD154-expressing fibroblasts described above. At the end of indicated incubation periods, cells were gently removed from the respective monolayers and analysed by flow cytometry using excitation and emission wavelengths of $488 \mathrm{~nm}$ and $517 \mathrm{~nm}$, respectively, according to manufacturer's protocol. FlowJo software (7.6.5 version) (FlowJo, Ashland, OR) was used to analyse proliferation data of CFSE-labelled CLL cells and calculate the percentage of divided cells, as described [39].

\section{Western blotting}

At the end of the incubation, co-cultured CLL cells were harvested and washed once in ice-cold phosphatebuffered saline (PBS) and lysed using $100 \mu$ of RIPA buffer (50 mM Tris/HCl (pH 7.6), 1\% (w/v) Triton-X100, 
$150 \mathrm{mM} \mathrm{NaCl}, 0.1 \%$ (w/v) sodium dodecyl sulfate $(\mathrm{SDS}), 0.5 \%(\mathrm{w} / \mathrm{v})$ sodium deoxycholate, and protease and phosphatase inhibitor cocktails (Sigma-Aldrich). Cell lysates were further sonicated using Diagenode Bioruptor ${ }^{\circledR}$ (Diagenode Inc, Liège, Belgium). Sonicated cell lysates were cleared of debris by centrifuging at $10,000 \mathrm{~g}$ for $10 \mathrm{~min}$ at $4^{\circ} \mathrm{C}$ and protein concentration determined using RC DC Protein Assay Reagents Kit (BioRad laboratories, Herts, UK). SDS polyacrylamide gel electrophoresis (SDS-PAGE) and immunoblotting were performed essentially as described [31]. Briefly, cellular proteins were separated on a SDS-polyacrylamide gel and transferred to Immobilon-P polyvinilidene difluoride membranes (Millipore Corporation, Bedford, MA) which were then probed with the appropriate primary antibodies. Immunoreactivity was detected using the relevant HRPlabelled secondary antibodies (Santa Cruz Biotechnology), which were visualized on an Image Reader LAS1000 (Fujifilm, Tokyo, Japan) using an enhanced chemiluminescence kit (Millipore). For quantification of the signals, the images were further analysed on the same instrument using 2D Densitometry Aida Image Analyzer software (Fujifilm).

\section{Statistical analysis}

Where appropriate, a two-tailed, paired $t$-test was performed to determine the statistical significance of the difference between the two groups of data.

\section{ACKNOWLEDGMENTS AND FUNDING}

This study was supported by research grants from AstraZeneca and Bloodwise (formerly Leukemia \& Lymphoma Research), UK. We are also grateful to Professor Gerald Cohen for his critical review of the manuscript.

\section{CONFLICTS OF INTEREST}

B.R.D. and P.K.S. are employees of AstraZeneca. J.Z. and A.R.P. have received research funding from AstraZeneca. The remaining authors declare no competing financial interests.

\section{REFERENCES}

1. Fabbri G, Dalla-Favera R. The molecular pathogenesis of chronic lymphocytic leukemia. Nat Rev Cancer. 2016; $16: 145-62$.

2. Hallek M, Fischer K, Fingerle-Rowson G, Fink AM, Busch R, Mayer J, Hensel M, Hopfinger G, Hess G, von Grünhagen U, Bergmann M, Catalano J, Zinzani PL, et al. Addition of rituximab to fludarabine and cyclophosphamide in patients with chronic lymphocytic leukemia: a randomised, openlabel, phase 3 trial. Lancet. 2010; 376:1164-74.

3. Chiorazzi N, Ferrarini M. Cellular origin(s) of chronic lymphocytic leukemia: cautionary notes and additional considerations and possibilities. Blood. 2011; 117:1781-91.

4. Seifert M, Sellmann L, Bloehdorn J, Wein F, Stilgenbauer S, Dürig J, Küppers R. Cellular origin and pathophysiology of chronic lymphocytic leukemia. J Exp Med. 2012; 209:2183-98.

5. Packham G, Stevenson F. The role of the B-cell receptor in the pathogenesis of chronic lymphocytic leukemia. Semin Cancer Biol. 2010; 20:391-9.

6. Herishanu Y, Pérez-Galán P, Liu D, Biancotto A, Pittaluga S, Vire B, Gibellini F, Njuguna N, Lee E, Stennett L, Raghavachari N, Liu P, McCoy JP, et al. The lymph node microenvironment promotes B-cell receptor signaling, NF-kappaB activation, and tumor proliferation in chronic lymphocytic leukemia. Blood. 2011; 117:563-74.

7. Zwick C, Fadle N, Regitz E, Kemele M, Stilgenbauer S, Bühler A, Pfreundschuh M, Preuss KD. Autoantigenic targets of B-cell receptors derived from chronic lymphocytic leukemias bind to and induce proliferation of leukemic cells. Blood. 2013; 121:4708-17.

8. Burger JA. Nurture versus nature: the microenvironment in chronic lymphocytic leukemia. Hematology Am Soc Hematol Educ Program. 2011; 2011:96-103.

9. Caligaris-Cappio F, Bertilaccio MT, Scielzo C. How the microenvironment wires the natural history of chronic lymphocytic leukemia. Semin Cancer Biol. 2014; 24:43-8.

10. Schattner EJ. CD40 ligand in CLL pathogenesis and therapy. Leuk Lymphoma. 2000; 37:461-72.

11. Furman RR, Asgary Z, Mascarenhas JO, Liou HC, Schattner EJ. Modulation of NF-kappa B activity and apoptosis in chronic lymphocytic leukemia B cells. J Immunol. 2000; 164:2200-6.

12. Srinivasan L, Sasaki Y, Calado DP, Zhang B, Paik JH, DePinho RA, Kutok JL, Kearney JF, Otipoby KL, Rajewsky K. PI3 kinase signals BCR-dependent mature B cell survival. Cell. 2009; 139:573-86.

13. Vanhaesebroeck B, Stephens L, Hawkins P. PI3K signalling: the path to discovery and understanding. Nat Rev Mol Cell Biol. 2012; 13:195-203.

14. Herman SE, Johnson AJ. Molecular pathways: targeting phosphoinositide 3-kinase p110-delta in chronic lymphocytic leukemia. Clin Cancer Res. 2012; 18:4013-8.

15. Burger JA. Targeting the microenvironment in chronic lymphocytic leukemia is changing the therapeutic landscape. Curr Opin Oncol. 2012; 24:643-9.

16. Barragán $\mathrm{M}$, Bellosillo $\mathrm{B}$, Campàs $\mathrm{C}$, Colomer $\mathrm{D}$, Pons G, Gil $\mathrm{J}$. Involvement of protein kinase $\mathrm{C}$ and phosphatidylinositol 3-kinase pathways in the survival of B-cell chronic lymphocytic leukemia cells. Blood. 2002; 99:2969-76. 
17. Ringshausen I, Schneller F, Bogner C, Hipp S, Duyster J, Peschel C, Decker T. Constitutively activated phosphatidylinositol-3 kinase (PI-3K) is involved in the defect of apoptosis in B-CLL: association with protein kinase Cdelta. Blood. 2002; 100:3741-8.

18. Brown JR, Byrd JC, Coutre SE, Benson DM, Flinn IW, Wagner-Johnston ND, Spurgeon SE, Kahl BS, Bello C, Webb HK, Johnson DM, Peterman S, Li D, et al. Idelalisib, an inhibitor of phosphatidylinositol 3-kinase p1108, for relapsed/refractory chronic lymphocytic leukemia. Blood. 2014; 123:3390-7.

19. Furman RR, Sharman JP, Coutre SE, Cheson BD, Pagel JM, Hillmen P, Barrientos JC, Zelenetz AD, Kipps TJ, Flinn I, Ghia P, Eradat H, Ervin T, et al. Idelalisib and rituximab in relapsed chronic lymphocytic leukemia. N Engl J Med. 2014; 370:997-1007.

20. O'Brien SM, Lamanna N, Kipps TJ, Flinn I, Zelenetz AD, Burger JA, Keating M, Mitra S, Holes L, Yu AS, Johnson DM, Miller LL, Kim Y, et al. A phase 2 study of idelalisib plus rituximab in treatment-naïve older patients with chronic lymphocytic leukemia. Blood. 2015; 126:2686-94.

21. Lannutti BJ, Meadows SA, Herman SE, Kashishian A, Steiner B, Johnson AJ, Byrd JC, Tyner JW, Loriaux MM, Deininger M, Druker BJ, Puri KD, Ulrich RG, et al. CAL-101, a p110delta selective phosphatidylinositol-3kinase inhibitor for the treatment of B-cell malignancies, inhibits PI3K signaling and cellular viability. Blood. 2011; 117:591-4.

22. Hoellenriegel J, Meadows SA, Sivina M, Wierda WG, Kantarjian H, Keating MJ, Giese N, O'Brien S, Yu A, Miller LL, Lannutti BJ, Burger JA. The phosphoinositide 3'-kinase delta inhibitor, CAL-101, inhibits B-cell receptor signaling and chemokine networks in chronic lymphocytic leukemia. Blood. 2011; 118:3603-12.

23. Till KJ, Pettitt AR, Slupsky JR. Expression of functional sphingosine-1 phosphate receptor-1 is reduced by B cell receptor signaling and increased by inhibition of PI3 kinase $\delta$ but not SYK or BTK in chronic lymphocytic leukemia cells. J Immunol. 2015; 194:2439-46.

24. Manning BD, Cantley LC. AKT/PKB signaling: navigating downstream. Cell. 2007; 129:1261-74

25. Fayard E, Xue G, Parcellier A, Bozulic L, Hemmings BA. Protein kinase B (PKB/Akt), a key mediator of the PI3K signaling pathway. Curr Top Microbiol Immunol. 2010; 346:31-56.

26. Hemmings BA, Restuccia DF. The PI3K-PKB/Akt pathway. Cold Spring Harb Perspect Biol. 2012; 4:a011189.

27. Hers I, Vincent EE, Tavaré JM. Akt signalling in health and disease. Cell Signal. 2011; 23:1515-27.

28. Cheung M, Testa JR. Diverse mechanisms of AKT pathway activation in human malignancy. Curr Cancer Drug Targets. 2013; 13:234-44.

29. Petlickovski A, Laurenti L, Li X, Marietti S, Chiusolo P, Sica S, Leone G, Efremov DG. Sustained signaling through the B-cell receptor induces Mcl-1 and promotes survival of chronic lymphocytic leukemia B cells. Blood. 2005; 105:4820-7.

30. Longo PG, Laurenti L, Gobessi S, Sica S, Leone G, Efremov DG. The Akt/Mcl-1 pathway plays a prominent role in mediating antiapoptotic signals downstream of the B-cell receptor in chronic lymphocytic leukemia B cells. Blood 2008; 111:846-55.

31. Zhuang J, Hawkins SF, Glenn MA, Lin K, Johnson GG, Carter A, Cawley JC, Pettitt AR. Akt is activated in chronic lymphocytic leukemia cells and delivers a prosurvival signal: the therapeutic potential of Akt inhibition. Haematologica. 2010; 95:110-8.

32. Hofbauer SW, Piñón JD, Brachtl G, Haginger L, Wang W, Jöhrer K, Tinhofer I, Hartmann TN, Greil R. Modifying akt signaling in B-cell chronic lymphocytic leukemia cells. Cancer Res. 2010; 70:7336-44.

33. de Frias M, Iglesias-Serret D, Cosialls AM, Coll-Mulet L, Santidrián AF, González-Gironès DM, de la Banda E, Pons G, Gil J. Akt inhibitors induce apoptosis in chronic lymphocytic leukemia cells. Haematologica. 2009; 94:1698-707.

34. Zhuang J, Laing N, Oates M, Lin K, Johnson G, Pettitt AR. Selective IAP inhibition results in sensitization of unstimulated but not CD40-stimulated chronic lymphocytic leukemia cells to TRAIL-induced apoptosis. Pharmacol Res Perspect. 2014; 2:e00081.

35. Herman SE, Gordon AL, Wagner AJ, Heerema NA, Zhao W, Flynn JM, Jones J, Andritsos L, Puri KD, Lannutti BJ, Giese NA, Zhang X, Wei L, et al. Phosphatidylinositol 3-kinase- $\delta$ inhibitor CAL-101 shows promising preclinical activity in chronic lymphocytic leukemia by antagonizing intrinsic and extrinsic cellular survival signals. Blood. 2010; 116:2078-88.

36. Liu TM, Ling Y, Woyach JA, Beckwith K, Yeh YY, Hertlein E, Zhang X, Lehman A, Awan F, Jones JA, Andritsos LA, Maddocks K, MacMurray J, et al. OSUT315: a novel targeted therapeutic that antagonizes AKT membrane localization and activation of chronic lymphocytic leukemia cells. Blood. 2015; 125:284-95.

37. Wu YT, Ouyang W, Lazorchak AS, Liu D, Shen HM, Su B. mTOR complex 2 targets Akt for proteasomal degradation via phosphorylation at the hydrophobic motif. J Biol Chem. $2011 ; 286: 14190-8$.

38. Worby CA, Dixon JE. PTEN. Annu Rev Biochem. 2014; 83:641-69.

39. Pascutti MF, Jak M, Tromp JM, Derks IA, Remmerswaal EB, Thijssen $\mathrm{R}$, van Attekum $\mathrm{MH}$, van Bochove GG, Luijks DM, Pals ST, van Lier RA, Kater AP, van Oers MH, et al. IL-21 and CD40L signals from autologous $\mathrm{T}$ cells can induce antigen-independent proliferation of CLL cells. Blood. 2013; 122:3010-9.

40. Cuní S, Pérez-Aciego P, Pérez-Chacón G, Vargas JA, Sánchez A, Martín-Saavedra FM, Ballester S, García-Marco J, 
Jordá J, Durántez A. A sustained activation of PI3K/ NF-kappaB pathway is critical for the survival of chronic lymphocytic leukemia B cells. Leukemia. 2004; 18:1391-400.

41. Davies BR, Greenwood H, Dudley P, Crafter C, Yu DH, Zhang J, Li J, Gao B, Ji Q, Maynard J, Ricketts SA, Cross D, Cosulich S, et al. Preclinical pharmacology of AZD5363, an inhibitor of AKT: pharmacodynamics, antitumor activity, and correlation of monotherapy activity with genetic background. Mol Cancer Ther. 2012; 11:873-87.

42. Knauf WU, Lissichkov $\mathrm{T}$, Aldaoud A, Liberati A, Loscertales J, Herbrecht R, Juliusson G, Postner G, Gercheva L, Goranov S, Becker M, Fricke HJ, Huguet F, et al. Phase III randomized study of bendamustine compared with chlorambucil in previously untreated patients with chronic lymphocytic leukemia. J Clin Oncol. 2009; 27:4378-84.

43. Eichhorst B, Fink AM, Bahlo J, Busch R, Kovacs G, Maurer C, Lange E, Köppler H, Kiehl M, Sökler M, Schlag R, Vehling-Kaiser U, Köchling G, et al. First-line chemoimmunotherapy with bendamustine and rituximab versus fludarabine, cyclophosphamide, and rituximab in patients with advanced chronic lymphocytic leukemia (CLL10): an international, open-label, randomised, phase 3, non-inferiority trial. Lancet Oncol. 2016; 17:928-42.

44. Hirai H, Sootome H, Nakatsuru Y, Miyama K, Taguchi S, Tsujioka K, Ueno Y, Hatch H, Majumder PK, Pan BS, Kotani H. MK-2206, an allosteric Akt inhibitor, enhances antitumor efficacy by standard chemotherapeutic agents or molecular targeted drugs in vitro and in vivo. Mol Cancer Ther. 2010; 9:1956-67.

45. Ding W, Shanafelt TD, Lesnick CE, Erlichman C, Leis JF, Secreto C, Sassoon TR, Call TG, Bowen DA, Conte M, Kumar S, Kay NE. Akt inhibitor MK2206 selectively targets CLL B-cell receptor induced cytokines, mobilizes lymphocytes and synergizes with bendamustine to induce CLL apoptosis. Br J Haematol. 2014; 164:146-50.

46. Vrhovac R, Delmer A, Tang R, Marie JP, Zittoun R, Ajchenbaum-Cymbalista F. Prognostic significance of the cell cycle inhibitor p27Kip1 in chronic B-cell lymphocytic leukemia. Blood. 1998; 91:4694-700.

47. Korz C, Pscherer A, Benner A, Mertens D, Schaffner C, Leupolt E, Döhner H, Stilgenbauer S, Lichter P. Evidence for distinct pathomechanisms in B-cell chronic lymphocytic leukemia and mantle cell lymphoma by quantitative expression analysis of cell cycle and apoptosis-associated genes. Blood. 2002; 99:4554-61.

48. Palacios F, Abreu C, Prieto D, Morande P, Ruiz S, Fernández-Calero $T$, Naya $H$, Libisch $G$, Robello $C$, Landoni AI, Gabus R, Dighiero G, Oppezzo P. Activation of the PI3K/AKT pathway by microRNA-22 results in CLL B-cell proliferation. Leukemia. 2015; 29:115-25.
49. Fingar DC, Salama S, Tsou C, Harlow E, Blenis J. Mammalian cell size is controlled by $\mathrm{mTOR}$ and its downstream targets S6K1 and 4EBP1/eIF4E. Genes Dev. 2002; 16:1472-87.

50. Faridi J, Fawcett J, Wang L, Roth RA. Akt promotes increased mammalian cell size by stimulating protein synthesis and inhibiting protein degradation. Am J Physiol Endocrinol Metab. 2003; 285:E964-72.

51. Edinger AL, Thompson CB. Akt maintains cell size and survival by increasing mTOR-dependent nutrient uptake. Mol Biol Cell. 2002; 13:2276-88.

52. Macallan DC, Wallace DL, Zhang Y, Ghattas H, Asquith B, de Lara C, Worth A, Panayiotakopoulos G, Griffin GE, Tough DF, Beverley PC. B-cell kinetics in humans: rapid turnover of peripheral blood memory cells. Blood. 2005; 105:3633-40.

53. van Gent R, Kater AP, Otto SA, Jaspers A, Borghans JA, Vrisekoop N, Ackermans MA, Ruiter AF, Wittebol S, Eldering E, van Oers MH, Tesselaar K, Kersten MJ, et al. In vivo dynamics of stable chronic lymphocytic leukemia inversely correlate with somatic hypermutation levels and suggest no major leukemic turnover in bone marrow. Cancer Res. 2008; 68:10137-44.

54. Messmer BT, Messmer D, Allen SL, Kolitz JE, Kudalkar P, Cesar D, Murphy EJ, Koduru P, Ferrarini M, Zupo S, Cutrona G, Damle RN, Wasil T, et al. In vivo measurements document the dynamic cellular kinetics of chronic lymphocytic leukemia B cells. J Clin Invest. 2005; 115:755-64.

55. Calissano C, Damle RN, Hayes G, Murphy EJ, Hellerstein MK, Moreno C, Sison C, Kaufman MS, Kolitz JE, Allen $\mathrm{SL}$, Rai KR, Chiorazzi N. In vivo intraclonal and interclonal kinetic heterogeneity in B-cell chronic lymphocytic leukemia. Blood. 2009; 114:4832-42.

56. Longo PG, Laurenti L, Gobessi S, Petlickovski A, Pelosi M, Chiusolo P, Sica S, Leone G, Efremov DG. The Akt signaling pathway determines the different proliferative capacity of chronic lymphocytic leukemia B-cells from patients with progressive and stable disease. Leukemia. 2007; 21:110-20.

57. Fecteau JF, Corral LG, Ghia EM, Gaidarova S, Futalan D, Bharati IS, Cathers B, Schwaederlé M, Cui B, LopezGirona A, Messmer D, Kipps TJ. Lenalidomide inhibits the proliferation of CLL cells via a cereblon/p21(WAF1/ Cip1)-dependent mechanism independent of functional p53. Blood. 2014; 124:1637-44.

58. Melarangi T, Zhuang J, Lin K, Rockliffe N, Bosanquet AG, Oates M, Slupsky JR, Pettitt AR. Glucocorticoid resistance in chronic lymphocytic leukemia is associated with a failure of upregulated Bim/Bcl-2 complexes to activate Bax and Bak. Cell Death Dis. 2012; 3:e372. 